\title{
The role of endoscopic ultrasound guided fine needle aspiration (EUS-FNA) in non small cell lung cancer (NSCLC) patients: SEED-SEPD-AEG Joint Guideline
}

\author{
Enrique Vázquez-Sequeiros ${ }^{1}$, Fernando González-Panizo Tamargo ${ }^{2}$, Ángel Barturen ${ }^{3}$, Ángel Calderón ${ }^{4}$, \\ José Miguel Esteban ${ }^{5}$, Gloria Fernández-Esparrach ${ }^{6}$, Antonio Gimeno-García ${ }^{7}$, Angels Ginés ${ }^{6}$, \\ José Lariño $^{8}$, Mercedes Pérez-Carreras ${ }^{9}$, Rafael Romero ${ }^{10}$, José Carlos Subtil ${ }^{11}$ and Juan Vila ${ }^{12}$ \\ ${ }^{I}$ Department of Gastroenterology. Hospital Ramón y Cajal. Madrid. Universidad de Alcalá, IRYCIS. Madrid, Spain. \\ ${ }^{2}$ Department of Gastroenterology. Hospital Universitario Quirón. Madrid. Spain. ${ }^{3}$ Department of Gastroenterology. \\ Hospital Cruces. Bilbao, Spain. ${ }^{4}$ Department of Gastroenterology. Hospital Basurto. Bilbao, Spain. ${ }^{5}$ Department of \\ Gastroenterology. Hospital Clínico San Carlos. Madrid, Spain. ${ }^{6}$ Unit of Endoscopy. Department of Gastroenterology. \\ Hospital Clinic. CIBEREHD. IDIBAPS. Universidad de Barcelona. Barcelona, Spain. ' Department of Gastroenterology. \\ Hospital Universitario. Tenerife, Spain. ${ }^{8}$ Department of Gastroenterology. Hospital Clínico. Santiago de Compostela, \\ Spain. ${ }^{9}$ Department of Gastroenterology. Hospital 12 de Octubre. Madrid, Spain. ${ }^{10}$ Department of Gastroenterology.

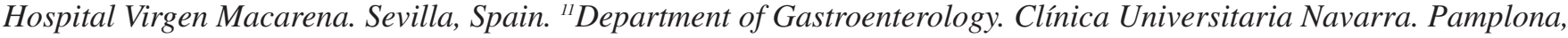 \\ Navarra. Spain. ${ }^{2}$ Servicio de Gastroenterología. Hospital de Navarra. Pamplona, Navarra. Spain
}

\begin{abstract}
Lung cancer is one of the most frequent neoplasms in our environment, and represents the first cause of cancer related death in western countries. Diagnostic and therapeutic approach to these patients may be complicated, with endoscopic ultrasound guided fine needle aspiration (EUS-FNA), classically performed by gastroenterologists, playing a very important role. As this disease is not closely related to the "digestive tract", gastroenterologists have been forced to update their knowledge on this field o adequately diagnose this significant group of patients. The recent advent of modern and promising techniques like endobronchial ultrasound guided fine needle aspiration (EBUS-FNA) have prompted new approaches for diagnosis and staging of this type of patients. In this clinical guideline, the "Sociedad Española de Endoscopia Digestiva" (SEED), "Sociedad Española de Patología Digestiva" (SEPD) and the "Asociación Española de Gastroenterología", have jointed efforts to update the existing knowledge on the field and provide their members with evidence based recommendations.
\end{abstract}

Key words: Endoscopic ultrasound. Fine needle aspiration. Lung cancer. Staging.

Received: 11-03-2013

Accepted: 27-03-2013

Correspondence: Enrique Vázquez-Sequeiros. Department of Gastroenterology. Hospital Universitario Ramón y Cajal. Ctra. de Colmenar Viejo, km 9,100. 28034 Madrid, Spain

e-mail: evazquezse@gmail.com

\section{INTRODUCTION}

Lung cancer is the most common cause of cancer related mortality (1). In Spain, it has been estimated that incidence of lung cancer is approximately 20,000 new cases per year, which represents the $12 \%$ of all neoplasms (1). Mortality associated with this type of tumor in our country reaches $20 \%$, higher than breast, prostate and colon cancer combined (1). Only about a third of these patients are amenable for surgical resection at the time of diagnosis and the overall 5 -year survival has been estimated in $15 \%$ (1).

For an adequate selection of candidates for surgery and/or neoadjuvant therapy, it is mandatory to obtain a tissue diagnosis confirmation of histology type and a tumor stage assessment. On figure 1 it is represented the most updated TNM Classification elaborated by the American Joint Commission on Cancer for the Lung Cancer (AJCC) that has been recently adopted by the "Sociedad Española de Patología del Aparato Respiratorio" (SEPAR) (2). As a general rule, stage I and II non-small cell lung

Vázquez-Sequeiros E, González-Panizo Tamargo F, Barturen A, Calderón A, Esteban JM, Fernández-Esparrach G, Gimeno-García A, Ginés A, Lariño J, Pérez-Carreras M, Romero R, Subtil JC, Vila J. The role of endoscopic ultrasound guided fine needle aspiration (EUS-FNA) in non small cell lung cancer (NSCLC) patients: SEED-SEPD-AEG Joint Guideline. Rev Esp Enferm Dig 2013;105:215-224. 
cancer (NSCLC) are treated by surgery alone, while radiotherapy maybe an option for cure in patients at this stage of disease that have a poor performance status or are unfit for surgery. Patients on stage III present an elevated risk of tumor recurrence if treated by surgery or radiotherapy alone. For this reason stage IIIA patients are initially treated with chemotherapy and surgery or radiotherapy being performed afterwards; and stage IIIB patients are usually treated with chemo and radiation therapy combined. Finally, those patients with a stage IV disease are typically offered palliative chemotherapy (3).

This therapeutic algorithm should give us an idea on how important is to obtain an adequate diagnosis and staging in this type of patients to better select the most adequate treatment for those affected by this deadly disease (Fig. 2).

\section{WHAT IS THE ROLE OF ENDOSCOPIC ULTRASOUND-GUIDED FINE NEEDLE ASPIRATION (EUS-FNA) IN PATIENTS WITH CLINICAL SUSPICION FOR LUNG CANCER?}

When a patient presents with a suspected lung cancer, further testing is usually indicated to histologically confirm diagnosis (tumor type) and to determine extension of the disease (tumor stage). Patient history, physical exam and laboratory testing are the initial steps when evaluating patients with suspicion for lung cancer (4). Afterwards, imaging of the lesion should be obtained to further characterize the primary lesion and its relationship with surrounding structures, to identify mediastinal lymph nodes suspicious for malignancy, and to exclude metastasis in the other lung, chest wall or in the upper abdomen (4). Computerized tomography (CT), either alone or combined with positron emission tomography (PET), and magnetic resonance imaging (MRI) are some of the techniques most frequently employed for this purpose (4). CT diagnosis of malignancy is based on size, and recent publications suggest that malignant nodes are those $\geq$ than $15 \mathrm{~mm}$ (2). Unfortunately, this size criterion is associated with a 40 $\%$ false positive rate and a $20 \%$ of false negative results (2). Although PET scan is not only based on size, but on lymph node metabolism, and subsequently has a higher sensitivity than CT, its false positive rate is as high as 25 $\%$ (4). Therefore, unfortunately, lung cancer diagnosis cannot be confirmed by non invasive tests, and to obtain a tissue diagnosis confirmation minimally invasive techniques (flexible bronchoscopy with forceps biopsy and/or blind transbronchial fine needle aspiration [TBNA], CTguided percutaneous fine needle aspiration [FNA , endoscopic ultrasound guided fine needle aspiration (EUSFNA), endobronchial ultrasound [EBUS] TBNA) or surgical exam (mediastinoscopy, thoracoscopy...) will be required (4). Selection of one technique or another for tissue diagnosis remains controversial, but certainly depends on several factors:
1. Performance characteristics of each test (diagnostic accuracy and safety)

2. Tumor location (central vs. peripheral).

3. Expertise available at each institution.

\section{EUS-FNA}

EUS-FNA may be useful in those patients who present a mediastinal mass or lymphadenopathy of unknown origin (benign $v s$. malignant) or have a non-small cell lung cancer that requires either cytologic confirmation or preoperative staging for treatment decision (5). Furthermore, the sample obtained by EUS-FNA may be employed not only for tumor histology assessment, but also for ancillary techniques such as immunohistochemistry or polimerase chain reaction. In those cases in which cytology is not conclusive, immunohistochemycal analysis in search for specific markers like TTF-1, p63 or CK5/6 may be helpful and increase diagnostic accuracy (6). A systematic review recently published, showed determination of endothelial growth factor receptor may predict response to tyrosine kinase in NSCLC patients (6). Whether histology needles may be better suited than cytology ones for immunohistochemical analysis, or may even preclude the need for onsite cytopathology assessment during procedure is unknown at present time.

EUS has been classically performed by gastroenterologists through the esophagus, allowing one to visualize and biopsy lesions located in the posterior and mid mediastinum (upper and lower paratracheal [stations 2 and 4L], aortopulmonary window [station 5], subcarinal [station 7], paraesophageal area [station 8], and inferior pulmonary ligament [station 9]) but not in the anterior mediastinum due to airway interposition that precludes US waves transmission $(5,6)$. Furthermore, when the echoendoscope is advanced into the gastric cavity, the upper part of the retroperitoneum (e.g. adrenal glands) is visualized and biopsies may be obtained if lesions are found at this level $(5,6)$.

Recent guidelines (2) from Pulmonologists Societies like the Spanish one, strongly recommend that: a) to explore the mediastinum in search for all nodes suspicious on PET-CT; b) the exam should be started by looking for $\mathrm{N} 3$ nodes, and continue with $\mathrm{N} 2$ and $\mathrm{N} 1$ nodes; c) nodes $\geq 5 \mathrm{~mm}$ should be sampled; d) a minimum of 3 passes per node are recommended before considering it negative; and e) if sample is contaminated, necrotic, bloody or insufficient, it should be considered indeterminate, and negativity should be confirmed by surgical techniques (2).

\section{EUS-FNA indications}

Due to its elevated diagnostic accuracy and safety, transoesophageal EUS-FNA is generally accepted nowadays as the standard in diagnosis of most mediastinal nodes and masses. The three main indications for EUS-FNA in the 


\section{Definitions}

Primary Tumor (T)

TX Primary tumor cannot be assessed, or tumor proven by the presence of malignant cells in sputum or bronchial washings but not visualized by imaging or bronchoscopy

TO No evidence of primary tumor

Tis Carcinoma in situ

T1 Tumor $3 \mathrm{~cm}$ or less in greatest dimension, surrounded by lung or visceral pleura, without bronchoscopic evidence of invasion more proximal than the lobar bronchus (for example, not in the main bronchus)'

T1a Tumor $2 \mathrm{~cm}$ or less in greatest dimension

T1b Tumor more than $2 \mathrm{~cm}$ but $3 \mathrm{~cm}$ or less in greatest dimension

T2 Tumor more than $3 \mathrm{~cm}$ but $7 \mathrm{~cm}$ or less or tumor with any of the following features (T2 tumors with these features are classified T2a if $5 \mathrm{~cm}$ or less): involves main bronchus, $2 \mathrm{~cm}$ or more distal to the carina; invades visceral pleura (PL1 or PL2); associated with atelectasis or obstructive pneumonitis that extends to the hilar region but does not involve the entire lung

T2a Tumor more than $3 \mathrm{~cm}$ but $5 \mathrm{~cm}$ or less in greatest dimension

T2b Tumor more than $5 \mathrm{~cm}$ but $7 \mathrm{~cm}$ or less in greatest dimension
T3 Tumor more than $7 \mathrm{~cm}$ or one that directly invades any of the following: parietal pleural (PL3), chest wall (including superio sulcus tumors), diaphragm, phrenic nerve, mediastinal pleura, parietal pericardium; 0 tumor in the main bronchus less than $2 \mathrm{~cm}$ distal to the carina' but without involvement of the carina; or associated atelectasis or obstructive pneumonitis of the entire lung or separate tumor nodule(s) in the same lobe

T4 Tumor of any size that invades any of the following: mediastinum, heart, great vessels, trachea, recurrent laryngeal nerve, esophagus, vertebral body, carina, separate tumor nodule(s) in a different ipsilateral lobe

\section{Distant Metastasis (M)}

M0 No distant metastasis

M1 Distant metastasis

M1a Separate tumor nodule(s) in a contralateral lobe, tumor with pleural nodules or malignant pleural (or pericardial) effusion ${ }^{2}$

M1b Distant metastasis (in extrathoracic organs)

\section{Notes}

The uncommon superficial spreading tumor of any size with its invasive component limited to the bronchial wall, which may exten proximally to the main bronchus, is also classified as Tla. 2 Most pleural (and pericardial) effusions with lung cancer are due to tumor. In a few patients, however, multiple cylopathologic examinations of pleurd not an exudate. Where these elements and dininial judgoment dictatat that the effusion is not related to the tumor, the effusion should be excluded as a staginn element and the patient should be classified as MO.
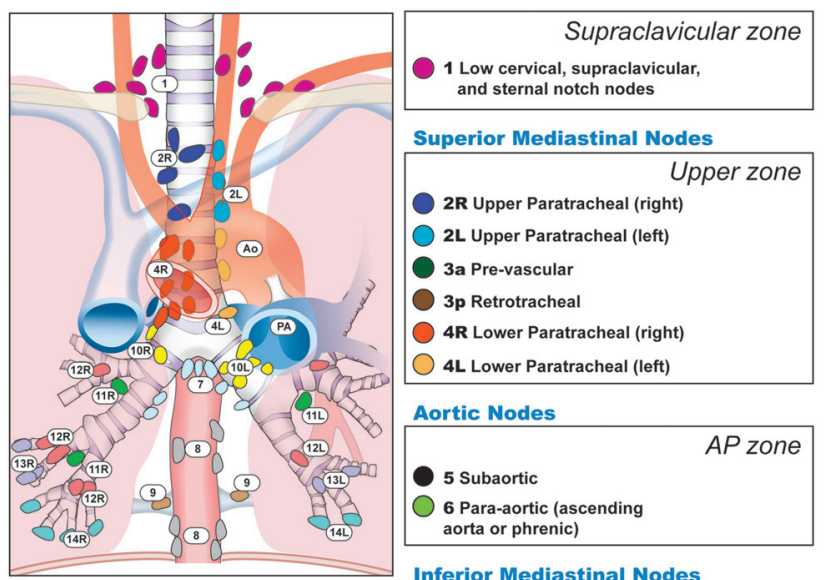

$$
\begin{aligned}
& \text { Regional Lymph Nodes (N) } \\
& \text { NK Regional lymph nodes } \\
& \text { cannot be assessed } \\
& \text { No No regional lymph } \\
& \text { node metastases } \\
& \text { N1 Metastasis in ipsilateral } \\
& \text { peribronchial and/or } \\
& \text { ipsilateral hilar lymph nodes } \\
& \text { and intrapulmonary nodes, } \\
& \text { including involvement } \\
& \text { by direct extension } \\
& \text { N2 Metastasis in ipsilateral } \\
& \text { mediastinal and/or } \\
& \text { subcarinal lymph node(s) } \\
& \text { N3 Metastasis in contralateral } \\
& \text { mediastinal, contralateral } \\
& \text { hilar, ipsilateral or } \\
& \text { contralateral scalene, or } \\
& \text { supraclavicular lymph node(s) }
\end{aligned}
$$

\begin{tabular}{|c|c|}
\hline $07 \mathrm{~s}$ & carinal zone \\
\hline & Lower zone \\
\hline \multicolumn{2}{|l|}{$\begin{array}{l}8 \text { Paraesophageal } \\
\text { (below carina) }\end{array}$} \\
\hline 9 Pulmonary ligament & \\
\hline
\end{tabular}

Superior Mediastinal Nodes

2R Upper Paratracheal (right)

2L Upper Paratracheal (left)

3a Pre-vascular

3p Retrotracheal

4R Lower Paratracheal (right)

4L Lower Paratracheal (left)

\begin{tabular}{|l|} 
Aortic Nodes \\
5 Subaortic \\
6 Para-aortic (ascending \\
aorta or phrenic)
\end{tabular}

Inferior Mediastinal Nodes
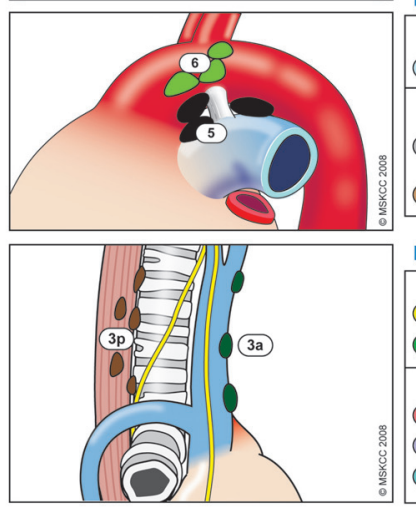

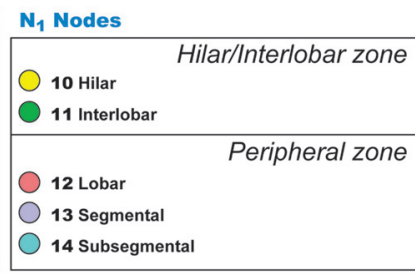

The IASLC Iymph node map shown with the proposed amalgamation of lymph into zones. (O) Memorial Sloan-Kettering
Cancer Center, 2009.)

Fig. 1. TNM Classification of NSCLC patients and schematic representation of mediastinal regions/stations (American Joint Committee on Cancer; 2009 ; 7th Edition). (Reprinted with permission from the AJCC) 


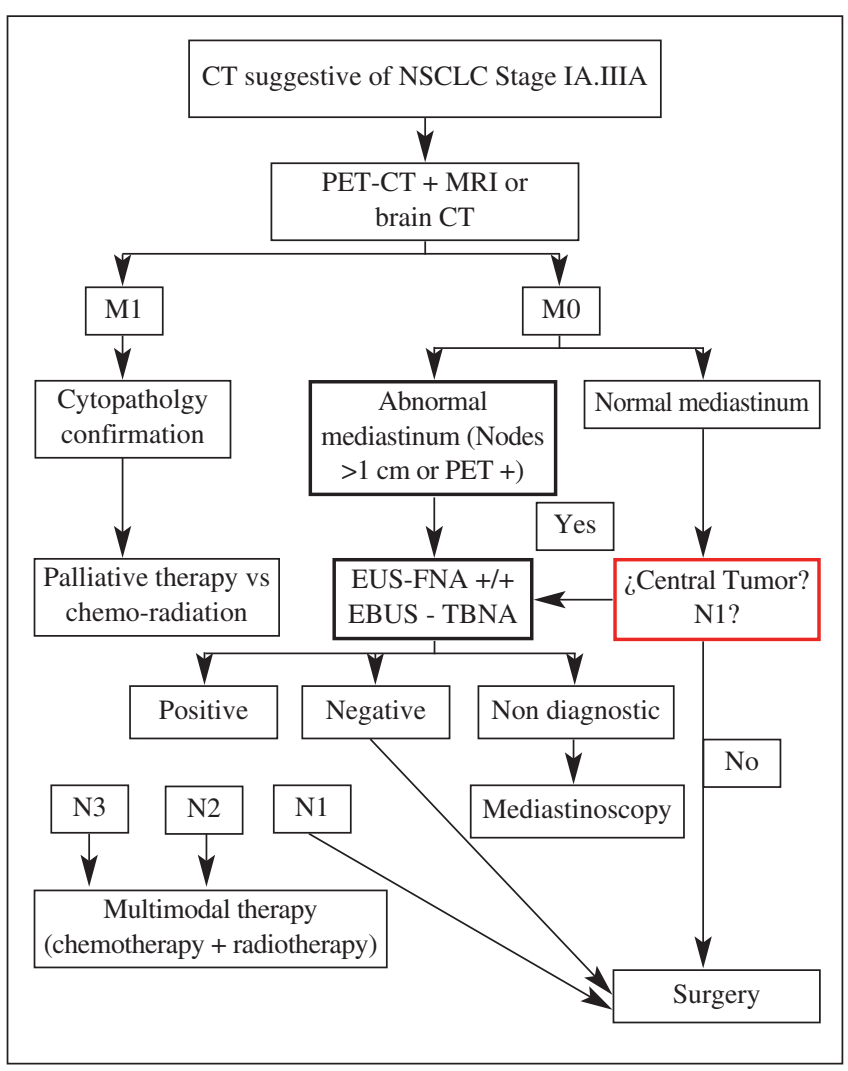

Fig. 2. Proposed algorithm for diagnosis and staging of NSCLC patients.

mediastinum are: a) diagnosis of mediastinal lymph nodes (stations 4L , 5, 7, 8, and 9) of unknown origin; b) staging of non small cell lung cancer (NSCLC); and c) biopsy of centrally located lung tumors (located in the vicinity of the esophagus).

\section{EUS-FNA in patients with prior non diagnostic blind TBNA}

It is important to highlight that EUS-FNA allows one to confidently diagnose the origin of the mediastinal lesion, either benign or malignant (NSCLC or another), even in those cases with prior non diagnostic blind TBNA (5-7). In a prospective cohort study, including a total of 50 patients with suspected sarcoidosis, Annema et al. demonstrated by means of EUS-FNA the presence sarcoidosis in $82 \%$ of patients $(71 \%$ had a prior non-diagnostic bronchoscopy) (8). EUS-FNA may also allow one to diagnose malignancy in mediastinal lymph nodes unrelated with lung cancer (metastasis from other type of tumor: esophageal, breast, renal cell cancer...), with a diagnostic accuracy as high as $96 \%$, according to prospective cohort studies (9). Although bronchoscopy is the initial diagnostic test in patients with clinical suspicion for lung cancer, at least $30 \%$ of times TBNA fails to reach a diagnosis. A recent meta-analysis including 13 studies evalu- ating the diagnostic usefulness of bronchoscopy TBNA in NSCLC, showed a sensitivity ranging from $39 \%$ to 78 $\%$ (95\% CI [17\%-84\%]), and a specificity of $99 \%(95$ $\%$ CI [96 \%-100\%]) (10). Moreover, one third of patients with lung cancer have mediastinal lymph nodes that after TBNA fails still need a diagnosis and staging as it is important for prognosis and allows to plan specific therapy in such patients. There is enough evidence in the literature supporting EUS-FNA is effective for diagnosis of these patients after TBNA has failed $(10,11)$. Data coming from prospective controlled studies have demonstrated that EUS-FNA is able to correctly diagnose malignancy in up to $96 \%$ of malignant cases $(10,11)$.

\section{EUS diagnosis of T4 NSCLC patients}

At present time, mediastinal tumor invasion is often assessed during surgery because CT scan has a very limited performance as well as PET-CT because of its limited anatomic resolution. Some reports have suggested EUS-FNA permits determine if the lung tumor invades mediastinal organs (e.g. left atrium), stage T4 that should contraindicate surgery, with a sensitivity and specificity of $87 \%$ and $98 \%$, respectively (12). In a cohort of 424 patients with suspected lung cancer, EUS had a sensitivity, specificity, positive predictive value, negative predictive value and accuracy of $39 \%, 100 \%, 100$ $\%, 92 \%$, and $92 \%$ in assessing T4 tumors (12).

\section{EUS-FNA in NSCLC patients with enlarged mediastinal lymph nodes on CT scan, or PET positive lymph nodes}

Patients with these features (enlarged or metabolically active nodes), will typically undergo sampling, as the sensitivity and specificity of imaging alone in the detection of lymph node metastasis is insufficient. Sensitivity, specificity and diagnostic accuracy of EUS-FNA in this clinical scenario has been estimated in a large number of prospective studies as high as 83-97 \%, 84-100 \%, and 94-97 \%, respectively (5-7,9-20). In summary, there is enough evidence supporting the fact that EUS-FNA plays a major role in the diagnosis and lymph node staging of lung cancer patients at present time, after CT or PET have identified nodal disease in the posterior mediastinum.

\section{EUS-FNA in NSCLC patients with no enlarged mediastinal lymph nodes on CT scan}

Although it does appear to be clear that EUS-FNA is indicated in the mediastinal staging of patients with suspected lung cancer, particularly in patients with enlarged (short axis $>10 \mathrm{~mm}$ ) lymph nodes or PET-positive lymph nodes, there is not a clear answer on what is the role of EUS-FNA on patients with node negative NSCLC on CT. Although, there 
are less data regarding this issue, some studies suggest that $20 \%$ of NSCLC patients with a negative CT scan do have malignant nodes at surgery (18,21-23). Prospective cohort studies conducted in 76 unselected patients have been able to prove that EUS-FNA is able to efficiently detect those metastasis $(25 \%$ in that cohort of patients with a negative CT) (23). Another prospective, controlled comparison study assessed the role of EUS and EUS-FNA in patients with CT node negative NSCLC (18). Eighty consecutive patients were evaluated, all of them underwent EUS and EUS-FNA exam. Diagnostic accuracy of EUS/EUS-FNA was $91 \%$, while CT was only $71 \%$. The negative predictive value of EUS-FNA was $92 \%$. Two of the patients evaluated presented a N3 NSCLA (even with a negative CT scan) (18). Similar results have been published in other prospective controlled comparisons between CT and EUS-FNA including 47 patients with NSCLC (22). Recent guidelines recommend to complete tumor staging in the following cases: a) after a negative PET-CT, except in the case of centrally located NSCLC as they usually contact with the mediastinum; and b) in tumors with low metabolism (2).

\section{EUS-FNA of distant lymph nodes in NSCLC patients}

EUS-FNA may also detect and biopsy lymph nodes in distant areas like the celiac region (classified as M1 disease by the TNM Classification). Results from a prospective controlled study conducted in over 113 lung cancer patients proved that $11 \%$ of patients had celiac nodes, and all of them were positive at EUS-FNA (vs. $50 \%$ for CT guided biopsy) (24). Preliminary reports, have also suggested that molecular analysis (CEA, CK19, KS1/4, lunx, muc 1, PDEF) may be conducted on samples obtained by means of EUS-FNA, and these analysis may help us identify unknown micrometastasis or even determine patient outcome (25).

\section{EUS-FNA for re-staging NSCLC patients}

Another special situation that may be found in clinical practice is the persistence of lymphadenopathy after treatment of malignancy. As this feature is not a definitive sign of tumor presence or recurrence, pathological sampling and diagnosis is essential for determining the appropriate treatment. In this regard, results from a recent publication comparing results of re-staging 28 NSCLC patients after chemoradiation therapy by CT/PET and EUS-FNA, showed that EUS-FNA had a $92.3 \%$ diagnostic accuracy and a $91.6 \%$ negative predictive value (26). Concordance between EUSFNA findings and metabolic response during FDG-PET of lymph node metastases occurred in approximately $50 \%$ of patients (26). These results support that restaging with EUSFNA after induction chemoradiotherapy reliably predicts the absence of nodal metastasis. However, other recent publication of a study on 58 patients showed less optimistic results, with a sensitivity and negative predictive value of $44 \%$ and $58 \%$, respectively (27).

\section{EUS-FNA of mediastinal lymph nodes safety}

A large number of studies, summarized in recently published guidelines, have demonstrated that EUS-FNA of mediastinal lesions is safe, especially for solid lesions (28). The complication rate of EUS-FNA was estimated in $0.5 \%$ for solid mediastinal masses or nodes and $14 \%$ for mediastinal cysts (28). Infection, hemorrhage or perforation are some of the complications that have been reported associated with this technique (28). Only 3 cases of tumor seed related to EUS-FNA have been reported, none of them happened in NSCLC patients (28)

\section{EBUS-TBNA vs. EUS-FNA}

EUS should be clearly distinguished from endobronchial ultrasound (EBUS), which is performed through the airway during bronchoscopy and, contrarily to EUS, permits an excellent visualization of the anterior mediastinum. EBUS is a more recent acquisition for tissue diagnosis that still is consolidating in clinical practice, and allows one to access and biopsy those areas that are blind to the classical transesophageal EUS. While EUS-FNA is generally performed by gastroenterologists, the EBUS-TBNA technique is typically conducted by pulmonologists. EBUS-TBNA permits one to obtain biopsies from mediastinal lymph nodes located in the paratracheal, subcarinal or hilar area in an effective and safe manner (29-32) (Fig. 1).

\section{Indications for EBUS-TBNA}

At present time, there are three main indications for EBUSTBNA: a) staging of NSCLC patients; b) tissue diagnosis of mediastinal masses and lymph nodes and endobronchial lesions; and c) guidance of endobronchial therapy (29-35).

\section{EBUS-TBNA compared with blind TBNA}

Prospective cohort studies conducted in 200 consecutive patients comparing EBUS-TBNA and blind TBNA have shown EBUS-TBNA to be more accurate at diagnosing these patients (84 vs. 58\%) (33). Similar results have been reported in meta-analysis including 11 observational studies with 1,299 patients (34).

\section{EBUS-TBNA compared with EUS-FNA}

Although results reported in the literature for EUS-FNA and EBUS-TBNA are excellent, it has to be acknowledged 
that each technique presents certain technical limitations that preclude one to sample all mediastinal regions (33-35). Both techniques sample different areas of the mediastinum, and it seems reasonable to use a combination of both techniques to obtain a complete mediastinal lymph node study when staging patients with NSCLC. In a prospective, blinded, comparative and controlled study including 138 patients with suspected lung cancer, the sensitivity of combined EUS-FNA + EBUS-TBNA (93\%), was significantly superior to that achieved by EUS-FNA alone, EBUS-TBNA alone, blind TBNA, blind TBNA + EBUS-TBNA, blind TBNA + EUS-FNA $(69 \%, 69 \%, 36 \%, 76 \%$ and $79 \%$, respectively) (35).

Based on literature results, it seems a reasonable approach to start with EUS-FNA when imaging techniques like CT suggest lymph nodes and/or masses are located in the lower or posterior mediastinum, while EBUS-TBNA should be preferred when target lesions are in the upper or anterior mediastinum (33-35). If EUS-FNA and/or EBUSTBNA are not available in a specific Institution, surgical techniques like mediastinoscopy should be employed for diagnosis (33-35). EBUS (using the radial miniprobe) may also be employed for tumor T staging in NSCLC or to diagnose extension in endobronchial lesions. When a peripheral pulmonary nodule is identified, EBUS-TBNA may be useful for imaging and biopsy (diagnostic accuracy greater than $70 \%)(36)$.

On the other hand, EUS-FNA has been shown to be very sensitive, accurate and safe for diagnosis of centrally located lung masses (diagnostic accuracy $97 \%$, and no complications in a prospective cohort including 32 patients) (37). EBUS-TBNA, as well as EUS-FNA, may be useful for diagnosis of sarcoidosis, as they may detect granulomas in the biopsy (38-40).

Diagnostic accuracy of these US guided techniques is superior to blind TBNA, EUS-FNA and EBUS-TBNA might qualify as the technique of choice to diagnose sarcoidosis.

\section{EBUS-TBNA of mediastinal lesions safety}

Safety of EBUS-TBNA is well documented in a systematic review of 18 observational studies including 1,782 patients (41). In that review, only minor complications (cough, agitation, blood at puncture site) were identified in $<1 \%$ of patients (41).

\section{Surgical techniques for mediastinal lymph node sampling}

Although it is not the aim of this guideline, it is important to be familiar with surgical techniques competing with EUS-FNA, and to understand advantages and limitations of each of them.

\section{Cervical mediastinoscopy}

Cervical mediastinoscopy is a surgical technique, not a minimally invasive test, that allows one to sample lymph nodes located in the upper paratracheal area (stations $2 \mathrm{R}$ and $2 \mathrm{~L}$ ), lower right and left paratracheal (station 4R and $4 \mathrm{~L}$ ), anterior part of the subcarinal area (station 7) and occasionally hilar nodes (stations 10R and 10L). Prospective cohort studies have shown mediastinoscopy has an elevated diagnostic yield (higher than $90 \%$, with $<5 \%$ complication rate) $(42,43)$. A recent publication of a prospective, randomized, multicenter trial including 241 NSCLC patients, directly compared the diagnostic staging accuracy of: a) "mediastinoscopy" vs. b) "EUS-FNA followed by EBUSTBNA and, in those negative cases, followed by mediastinoscopy" (43). Sensitivity of mediastinoscopy alone was significantly lower than the combined strategy (79\%, $95 \%$ CI [66 \% -88 \%] vs. $94 \%, 95 \%$ CI [85 \% -98\%] respectively; $p=0,02)$. Overall, the sensitivity of medastinoscopy was lower than EUS-FNA/EBUS-TBNA $(80 \%, 95 \%$ CI [68 \% - $89 \%]$ vs. $94 \%, 95 \%$ CI [85\% $98 \%$ ] respectively; $p=0.04$ ). Furthermore, it should be mentioned that the combined strategy decreased two times the need for thoracotomies.

\section{Mediastinotomy and thoracoscopy}

Other surgical techniques such as anterior mediastinotomy (samples station 4L, subaortic/station 5, paraaortic/station 6, and subcaribal area/station 7) or thoracoscopy (samples azigos/station 4R, station 5, 6, paraesophageal/station 8 and pulmonary ligament/station 9) are only used when other less invasive tests (e.g. EUS-FNA, EBUS-TBNA...) are unable to reach a diagnosis. Thoracoscopy has been proven in prospective cohort studies to be more reliable than radiologic tests for detection of pleural or mediastinum involvement (44-46). Prospective cohort studies have shown thoracoscopy significantly improves staging accuracy in patients with suspected stage IIIB NSCLC (46).

However, at present time, most lung cancer patients will be diagnosed by means of non invasive tests (like EUSFNA or EBUS-TBNA) in an outpatient basis, reducing the costs and risks of this type of techniques. For this reason, mediastinoscopy, mediastinotomy and thoracoscopy are generally reserved only for those cases in which minimally invasive tests have failed $(42,43)$.

\section{Pleural effusion in NSCLC patients}

When staging a patient with a lung cancer, it is not infrequent that a pleural effusion is found in the preoperative work up. In patients with a clinical suspicion for NSCLC is mandatory to puncture this pleural effusion to exclude a malignant origin. It has been estimated that approximately $65 \%$ of them will be malignant, and may require even more 
than one thoracentesis or a thoracoscopy and biopsy to establish a definitive diagnosis (47-51). EUS provides excellent visualization of both pleuras, and EUS-FNA may be performed in a safely and accurate manner from the esophagus as shown in prospective studies (47-51).

\section{Adrenal gland metastasis in NSCLC patients}

Another important point when evaluating a patient with NSCLC is the evaluation of the adrenal glands (27-29). It has been estimated that at least $4 \%$ of NSCLC patients will present a nodule in the adrenal gland at the time of diagnosis $(52,53)$. CT scan and MRI have shown in prospective cohort studies a sensitivity, and specificity to detect adrenal nodules that ranges from $98 \%-100 \%$ and $92 \%-95 \%$, respectively (54-56). PET scan is also very accurate for detection of adrenal gland metastasis in NSCLC patients (92-93\%) (57). At present time, EUS-FNA is the technique of choice for tissue diagnosis confirmation of adrenal gland metastasis $(58,59)$. This is due to its elevated diagnostic accuracy and less than $1 \%$ rate of complications as shown in prospective cohort studies evaluating consecutive unselected patients (58). In that study, EUS-FNA of the adrenal gland modified the TNM staging of the patient in $70 \%$ of cases, and the treatment in $48 \%$ of them (gained surgery $25 \%$, avoided surgery $5 \%$, surgically verified benign disease $5 \%$, no cancer and no further work up 5\%, and no cancer, control computed tomography, and then no further workup $8 \%$ ) (58). A malignant left adrenal gland lesion was found in $28 \%$ and was significantly associated with shorter survival, making authors conclude that EUS-FNA of an enlarged adrenal gland in patients with known or suspected NSCLC had a significant impact on TNM staging, treatment, and survival. Recent guidelines recommend to sample enlarged adrenal glands (left or right), only on those cases in which cytology result may have an impact on patient management $(2,28)$.

\section{Impact of EUS-FNA on NSCLC patient management and cost}

A number of studies have been reported investigating the impact of EUS-FNA on patient management and cost $(60,61)$. A total of 213 consecutive patients with mediastinal nodes were evaluated in a retrospective study, and a positive EUS-FNA result was obtained in $84 \%$ of patients, resulting in a modification of patient therapy in all of them (84\%), with no impact in the remaining patients (16\%) (61). Authors estimated that by performing EUS-FNA in that cohort of patients, a reduction in cost of $€ 100.593$ was obtained, with a mean cost reduction of $€ 472$ (SD $=€ 607$ ) per patient. Similar results were demonstrated in a cost minimization analysis comparing EUS-FNA vs. EUS-FNA combined with EBUS-TBNA vs. bronchoscopy and mediastinoscopy (61). This study evidenced that the combination EUS-FNA/EBUS-TBNA was the most economical approach for patients with suspected NSCLC. Sensitivity analysis also demonstrated that if probability of malignant lymph nodes is less than $32.9 \%$ (like in patients with a CTscan with no nodes larger than $10 \mathrm{~mm}$ ), EUS-FNA would be the most economic technique. However, if pre-test probability of having malignant lymph nodes in superior to that percentage (like in those cases with enlarged nodes on CTscan), the combination EUS-FNA/EBUS-TBNA is the most economic strategy for diagnosis (61). Prior studies were also able to prove that in patients with mediastinal lymphadenopathy EUS-FNA is the most economic test to obtain a tissue diagnosis confirmation when prevalence of malignant nodes exceeds $24 \%$ or EUS-FNA sensitivity is above $76 \%$ (62). If prevalence of malignancy is below $24 \%$ or EUS-FNA sensitivity does not reach $76 \%$, mediastinoscopy is the most economic approach (62). In a recent prospective, multicenter study conducted on 241 patients with resectable NSCLC, authors demonstrated that the rate of futile thoracotomies was reduced from $18 \%$ to $7 \%$ if EUS-FNA was performed (63).

\section{Who should be trained to perform biopsies in NSCLC patients}

Finally, there is an opened discussion about the person who should perform the biopsy in lung cancer patients. The answer for such a question is not straight forward. There is no doubt that NSCLC and other mediastinal lesions will require an expert in pulmonology for best diagnosis and treatment, and gastroenterologists are not adequately prepared to be in charge of these patients. Pulmonologists have classically relied on blind-TBNA for diagnosing these patients, but results have been clearly unsatisfactory, due to the blindness of the technique and inaccessibility to certain stations. With the advent of EBUS-TBNA following a transbronchial route, the blindness limitation has been solved and pulmonologist performance has dramatically increased (33-35). Gastroenterologists have been performing transesophageal EUS-FNA for about two decades, and have proven that EUS-FNA reaches most stations located in the posterior and mid mediastinum and infradiaphragmatic area with excellent results (5-9). As this technique is widely available at present time in Gastroenterology Units, and there is growing evidence that a combined approach (EUS-FNA/EBUSTBNA) obtains the best results in terms of sensitivity, accuracy, impact on therapy and cost, we would advocate to make a reasonable use of both techniques (33-35). If lymph nodes are located in the anterior/superior mediastinum, we would recommend to directly select EBUS-TBNA, and if located in other areas, select EUS-FNA. Although a personal opinion, it seems reasonable that pulmonologists and not gastroenterologists perform the transbronchial approach (EBUS-TBNA), and gastroenterologists, more familiarized with the transesophageal route perform EUS-FNA. As EUS-FNA and EBUS-TBNA may have a significant 
impact on patient management, it is our believe that there is a crucial need to spread the technique from specialized centers with experience in both of them.

\section{SUMMARY AND RECOMMENDATIONS}

1. Transesophageal EUS-FNA permits visualize and biopsy lesions located in the posterior and mid mediastinum in a safe and effective manner, even in those cases with prior non diagnostic blind TBNA. Evidence level $2++$, Recommendation grade $B$.

2. EUS-FNA has been proven to be highly sensitive, specific and accurate for diagnosis of patients with enlarged mediastinal lymph nodes on CT scan (> $10 \mathrm{~mm}$ ), or PET positive (metabolically active nodes). Evidence level $2++$, Recommendation grade $B$.

3. The use of EUS-FNA should be recommended in NSCLC patients with a negative CT scan, as EUSFNA is able to detect unknown metastasis in up to $25 \%$ of them. Evidence level $2++$, Recommendation grade $B$.

4. EUS-FNA has been proven to be useful to assess patient response to neoadjuvant therapy (negative predictive value 70-90\%). Evidence level $2++$, Recommendation grade $B$.

5. The combination of EUS-FNA and EBUS-TBNA is the most accurate method for minimally invasive diagnosis and staging of lung cancer patients. It is recommended to start sampling those lesions that may provide the most advanced tumor stage. Evidence level $1+$, Recommendation grade A.

6. EUS-FNA of centrally located lung masses is safe and accurate and should be more frequently indicated (diagnostic accuracy: $97 \%$ ). Evidence level 2-, Recommendation grade $C$.

7. Surgical techniques (mediastinoscopy, mediastinotomy or thoracoscopy) should be reserved only for those cases in which less invasive tests (e.g. EUSFNA, EBUS-TBNA...) are unable to reach a diagnosis. Evidence level 4, Recommendation grade D.

8. EUS provides excellent visualization of both pleuras, and EUS-FNA of pleural effusions may be performed in a safely and accurate manner from the esophagus. Evidence level 3, Recommendation grade $D$.

9. In patients with NSCLC, EUS-FNA is the technique of choice for tissue diagnosis confirmation of adrenal gland metastasis. In this clinical setting, EUSFNA will have a significant impact on TNM staging, treatment, and patient survival. Evidence level 2+, Recommendation grade $C$.

10. Cost analysis studies have evidenced that the combination EUS-FNA/EBUS-TBNA is the most economical approach for patients with suspected NSCLC if pre-test probability of having malignant lymph nodes is less than $32.9 \%$ (e.g. patients with a CT-scan with no nodes larger than $10 \mathrm{~mm}$ ). If a prevalence $>32-9 \%$ of malignant lymph nodes is expected, EUS-FNA would be the most economic technique. Evidence level 1+, Recommendation grade $A$.

11. If lymph nodes are located in the posterior mediastinum, EUS-FNA should be employed as the first diagnostic test for tissue diagnosis confirmation. For other locations, EBUS-TBNA should be recommended. Evidence level 1+, Recommendation grade A.

\section{REFERENCES}

1. Jemal A, Bray F, Center MM, Ferlay J, Ward E, Forman D. Global cancer statistics. Cancer J Clin 2011;61:69-90.

2. Sánchez de Cos J, Hernández Hernández J, Jiménez López MJ, Padrones Sánchez S, Rosell Gratacós A, Rami Porta R. Normativa SEPAR sobre estadificación de cáncer de pulmón. Arch Bronconeumol 2011;47:454-65.

3. Trigo Pérez JM, Garrido López P, Felip Font E, Isla Casado D; SEOM (Spanish Society for Medical Oncology). SEOM clinical guidelines for the treatment of non-small-cell lung cancer: an updated edition. Clin Transl Oncol 2010;12:735-41.

4. Rivera MP, Mehta AC, American College of Chest Physicians. Initial diagnosis of lung cancer: ACCP evidence-based clinical practice guidelines (2nd edition). Chest 2007; 132:131S.

5. Pedersen BH, Vilmann P, Folke K, Jacobsen GK, Krasnik M, Milman $\mathrm{N}$, Hancke S. Endoscopic ultrasonography and real-time guided fineneedle aspiration biopsy of solid lesions of the mediastinum suspected of malignancy. Chest 1996; 110:539-44.

6. Ellis PM, Blais N, Soulieres D, Ionescu DN, Kashyap M, Liu G, et al. A systematic review and Canadian consensus recommendations on the use of biomarkers in the treatment of non-small cell lung cancer. J Thorac Oncol 2011;6:1379-91

7. Eloubeidi MA, Cerfolio RJ, Chen VK, Desmond R, Syed S, Ojha B. Endoscopic ultrasound-guided fine needle aspiration of mediastinal lymph node in patients with suspected lung cancer after positron emission tomography and computed tomography scans. Ann Thorac Surg 2005;79:263-8.

8. Annema JT, Veseliç M, Rabe KF. Endoscopic ultrasound-guided fineneedle aspiration for the diagnosis of sarcoidosis. Eur Respir J 2005; 25:405-9.

9. Devereaux BM, Leblanc JK, Yousif E, Kesler K, Brooks J, Mathur $\mathrm{P}$, et al. Clinical utility of EUS-guided fine-needle aspiration of mediastinal masses in the absence of known pulmonary malignancy. Gastrointest Endosc 2002; 56:397-401.

10. Holty JE, Kuschner WG, Gould MK. Accuracy of transbronchial needle aspiration for mediastinal staging of non-small cell lung cancer: a metaanalysis. Thorax 2005; 60: 949-55.

11. Annema J, Veseliç M, Rabe K. EUS-guided FNA of centrally located lung tumours following a non-diagnostic bronchoscopy. Lung Cancer 2005;48:357-61.

12. Varadarajulu S, Schmulewitz N, Wildi SM, Roberts S, Ravenel J, Reed CE, et al. Accuracy of EUS in staging of T4 lung cancer. Gastrointest Endosc 2004;59:345-8.

13. Wallace MB, Silvestri GA, Sahai AV, Hawes RH, Hoffman BJ, Durkalski V, et al. Endoscopic ultrasound-guided fine needle aspiration for staging patients with carcinoma of the lung. Ann Thorac Surg 2001;72:1861-7.

14. Larsen SS, Krasnik M, Vilmann P, Jacobsen GK, Pedersen JH, Faurschou $\mathrm{P}$, et al. Endoscopic ultrasound guided biopsy of mediastinal lesions has a major impact on patient management. Thorax 2002;57:98-103.

15. Giovannini M, Seitz JF, Monges G, Perrier H, Rabbia I. Fine-needle aspiration cytology guided by endoscopic ultrasonography: results in 141 patients. Endoscopy 1995;27:171-7. 
16. Wiersema MJ, Vazquez-Sequeiros E, Wiersema LM. Evaluation of mediastinal lymphadenopathy with endoscopic US-guided fine-needle aspiration biopsy. Radiology 2001;219:252-7.

17. Wallace MB, Fritscher-Ravens A, Savides TJ. Endoscopic ultrasound for the staging of non-small-cell lung cancer. Endoscopy 2003;35:60610.

18. Yasuda I, Kato T, Asano F, Okubo K, Omar S, Kako N, et al. Mediastinal lymph node staging in potentially resectable non-small cell lung cancer: A prospective comparison of CT and EUS/EUS-FNA. Respiration 2009;78:423-31.

19. Gress FG, Savides TJ, Sandler A, Kesler K, Conces D, Cummings O, et al. Endoscopic ultrasonography, fine-needle aspiration biopsy guided by endoscopic ultrasonography, and computed tomography in the preoperative staging of non-small-cell lung cancer: A comparison study. Ann Intern Med 1997; 127:604-12.

20. Fritscher-Ravens A, Bohuslavizki KH, Brandt L, Bobrowski C, Lund C, Knöfel WT, et al. Mediastinal lymph node involvement in potentially resectable lung cancer: Comparison of CT, positron emission tomography, and endoscopic ultrasonography with and without fine-needle aspiration. Chest 2003;123:442-51.

21. Kondo D, Imaizumi M, Abe T, Naruke T, Suemasu K. Endoscopic ultrasound examination for mediastinal lymph node metastases of lung cancer. Chest 1990;98:586-93.

22. Fernández-Esparrach G, Ginès A, Belda J, Pellisé M, Solé M, Marrades $\mathrm{R}$, et al. Transesophageal ultrasound-guided fine needle aspiration improves mediastinal staging in patients with non-small cell lung cancer and normal mediastinum on computed tomography. Lung Cancer 2006;54:35-40

23. LeBlanc JK, Devereaux BM, Imperiale TF, Kesler K, DeWitt JM, Cummings $\mathrm{O}$, et al. Endoscopic ultrasound in non-small cell lung cancer and negative mediastinum on computed tomography. Am J Respir Crit Care Med 2005; 171:177-82.

24. Singh P, Camazine B, Jadhav Y, Gupta R, Mukhopadhyay P, Khan A, et al. Endoscopic ultrasound as a first test for diagnosis and staging of lung cancer: A prospective study. Am J Respir Crit Care Med 2007; 175:345-54.

25. Wallace MB, Block MI, Gillanders W, Ravenel J, Hoffman BJ, Reed $\mathrm{CE}$, et al. Accurate molecular detection of non-small cell lung cancer metastases in mediastinal lymph nodes sampled by endoscopic ultrasound-guided needle aspiration. Chest 2005; 127:430-7.

26. Stigt JA, Oostdijk AH, Timmer PR, Shahin GM, Boers JE, Groen HJ. Comparison of EUS-guided fine needle aspiration and integrated PETCT in restaging after treatment for locally advanced non-small cell lung cancer. Lung Cancer 2009;66:198-204.

27. von Bartheld MB, Versteegh MI, Braun J, Willems LN, Rabe KF, Annema JT. Transesophageal ultrasound-guided fine-needle aspiration for the mediastinal restaging of non-small cell lung cancer. $\mathrm{J}$ Thorac Oncol 2011;6:1510-5.

28. Dumonceau JM, Polkowski M, Larghi A, Vilmann P, Giovannini M, Frossard JR, et al. Indications, results, and clinical impact of endoscopic ultrasound (EUS)-guided sampling in gastroenterology: European Society of Gastrointestinal Endoscopy (ESGE) Clinical Guide. Endoscopy 2011;43:897-909.

29. Herth FJ, Eberhardt R, Vilmann P, Krasnik M, Ernst A. Real-time endobronchial ultrasound guided transbronchial needle aspiration for sampling mediastinal lymph nodes. Thorax 2006;61:795-8.

30. Herth FJ, Ernst A, Eberhardt R, Vilmann P, Dienemann H, Krasnik M. Endobronchial ultrasound-guided transbronchial needle aspiration of lymph nodes in the radiologically normal mediastinum. Eur Respir J 2006;28:910-4.

31. Yasufuku K, Nakajima T, Motoori K, Sekine Y, Shibuya K, Hiroshima $\mathrm{K}$, et al. Comparison of endobronchial ultrasound, positron emission tomography, and CT for lymph node staging of lung cancer. Chest 2006;130:710-8.

32. Yasufuku K, Chiyo M, Koh E, Moriya Y, Iyoda A, Sekine Y, et al. Endobronchial ultrasound guided transbronchial needle aspiration for staging of lung cancer. Lung Cancer 2005;50:347-54.

33. Herth F, Becker HD, Ernst A. Conventional vs. endobronchial ultrasound-guided transbronchial needle aspiration: A randomized trial. Chest 2004;125:322-5.

34. Gu P, Zhao YZ, Jiang LY, Zhang W, Xin Y, Han BH. Endobronchial ultrasound-guided transbronchial needle aspiration for staging of lung cancer: A systematic review and meta-analysis. Eur J Cancer 2009; 45:1389-96.

35. Wallace MB, Pascual JM, Raimondo M, Woodward TA, McComb BL, Crook JE, et al. Minimally invasive endoscopic staging of suspected lung cancer. JAMA 2008;299:540-6.

36. Herth FJ, Eberhardt R, Becker HD, Ernst A. Endobronchial ultrasoundguided transbronchial lung biopsy in fluoroscopically invisible solitary pulmonary nodules: A prospective trial. Chest 2006;129:147-50.

37. Annema JT, Veseliç M, Rabe KF. EUS-guided FNA of centrally located lung tumours following a non-diagnostic bronchoscopy. Lung Cancer 2005;48:357-61.

38. Tremblay A, Stather DR, Maceachern P, Khalil M, Field SK. A randomized controlled trial of standard vs. endobronchial ultrasonography-guided transbronchial needle aspiration in patients with suspected sarcoidosis. Chest 2009;136:340-6.

39. Wong M, Yasufuku K, Nakajima T, Herth FJ, Sekine Y, Shibuya K, et al. Endobronchial ultrasound: New insight for the diagnosis of sarcoidosis. Eur Respir J 2007;29:1182-6.

40. Nakajima T, Yasufuku K, Kurosu K, Takiguchi Y, Fujiwara T, Chiyo $\mathrm{M}$, et al. The role of EBUS-TBNA for the diagnosis of sarcoidosiscomparisons with other bronchoscopic diagnostic modalities. Respir Med 2009;103:1796-800.

41. Kurimoto N, Miyazawa T, Okimasa S, Maeda A, Oiwa H, Miyazu Y, et al. Endobronchial ultrasonography using a guide sheath increases the ability to diagnose peripheral pulmonary lesions endoscopically. Chest 2004;126:959-65.

42. Little AG, Rusch VW, Bonner JA, Gaspar LE, Green MR, Webb WR, Stewart AK. Patterns of surgical care of lung cancer patients. Ann Thorac Surg 2005;80:2051-6.

43. Annema JT, van Meerbeeck JP, Rintoul RC, Dooms C, Deschepper E, Dekkers OM, et al. Mediastinoscopy vs endosonography for mediastinal nodal staging of lung cancer: A randomized trial. JAMA 2010; 304:2245-52.

44. Wain JC. Video-assisted thoracoscopy and the staging of lung cancer. Ann Thorac Surg 1993;56:776-8.

45. Roberts JR, Blum MG, Arildsen R, Drinkwater DC Jr, Christian $\mathrm{KR}$, Powers TA, et al. Prospective comparison of radiologic, thoracoscopic, and pathologic staging in patients with early non-small cell lung cancer. Ann Thorac Surg 1999;68:1154-8.

46. De Giacomo T, Rendina EA, Venuta F, Della Rocca G, Ricci C. Thoracoscopic staging of IIIB non-small cell lung cancer before neoadjuvant therapy. Ann Thorac Surg 1997;64:1409-11.

47. Pretreatment evaluation of non-small-cell lung cancer. The American Thoracic Society and the European Respiratory Society. Am J Respir Crit Care Med 1997;156:320-32.

48. Ohnishi R, Yasuda I, Kato T, Tanaka T, Kaneko Y, Suzuki T, et al. Combined endobronchial and endoscopic ultrasound guided fine needle aspiration for mediastinal nodal staging of lung cancer. Endoscopy 2011;43:1082-9.

49. British Thoracic Society, Society of Cardiothoracic Surgeons of Great Britain and Ireland Working Party. BTS guidelines: guidelines on the selection of patients with lung cancer for surgery. Thorax 2001;56:89-108.

50. Menzies R, Charbonneau M. Thoracoscopy for the diagnosis of pleural disease. Ann Intern Med 1991;114:271-6.

51. Prakash UB, Reiman HM. Comparison of needle biopsy with cytologic analysis for the evaluation of pleural effusion: Analysis of 414 cases. Mayo Clin Proc 1985;60:158-64.

52. Bovio S, Cataldi A, Reimondo G, Sperone P, Novello S, Berruti A, et al. Prevalence of adrenal incidentaloma in a contemporary computerized tomography series. J Endocrinol Invest 2006;29:298-302.

53. Lam KY, Lo CY. Metastatic tumours of the adrenal glands: A 30-year experience in a teaching hospital. Clin Endocrinol (Oxf) 2002;56:95101.

54. Porte HL, Ernst OJ, Delebecq T, Métois D, Lemaitre LG, Wurtz AJ Is computed tomography guided biopsy still necessary for the diagnosis of adrenal masses in patients with resectable non-small-cell lung cancer? Eur J Cardiothorac Surg 1999;15:597-601.

55. Caoili EM, Korobkin M, Francis IR, Cohan RH, Platt JF, Dunnick NR, et al. Adrenal masses: Characterization with combined unenhanced and delayed enhanced CT. Radiology 2002;222:629-33.

56. Blake MA, Kalra MK, Sweeney AT, Lucey BC, Maher MM, Sahani $\mathrm{DV}$, et al. Distinguishing benign from malignant adrenal masses: mul- 
ti-detector row CT protocol with 10-minute delay. Radiology 2006; 238:578-85.

57. Kumar R, Xiu Y, Yu JQ, Takalkar A, El-Haddad G, Potenta S, et al. 18F-FDG PET in evaluation of adrenal lesions in patients with lung cancer. J Nucl Med 2004;45:2058-62.

58. Bodtger U, Vilmann P, Clementsen P, Galvis E, Bach K, Skov BG. Clinical impact of endoscopic ultrasound-fine needle aspiration of left adrenal masses in established or suspected lung cancer. J Thorac Oncol 2009;4:1485-9.

59. Schuurbiers OC, Tournoy KG, Schoppers HJ, Dijkman BG, Timmers HJ, de Geus-Oei LF, et al. EUS-FNA for the detection of left adrenal metastasis in patients with lung cancer. Lung Cancer 2011;73:3105 .

60. Hirdes MM, Schwartz MP, Tytgat KM, Schlösser NJ, Sie-Go DM, Brink MA, et al. Performance of EUS-FNA for mediastinal lym- phadenopathy: Impact on patient management and costs in low-volume EUS centers. Surg Endosc 2010;24:2260-7.

61. Harewood GC, Pascual J, Raimondo M, Woodward T, Johnson $\mathrm{M}, \mathrm{McComb} \mathrm{B}$, et al. Economic analysis of combined endoscopic and endobronchial ultrasound in the evaluation of patients with suspected non-small cell lung cancer. Lung Cancer 2010;67:366-71.

62. Harewood GC, Wiersema MJ, Edell ES, Liebow M. Cost-minimization analysis of alternative diagnostic approaches in a modeled patient with non-small cell lung cancer and subcarinal lymphadenopathy. Mayo Clin Proc 2002;77:155-64.

63. Sharples LD, Jackson C, Wheaton E, Griffith G, Annema JT, Dooms $\mathrm{C}$, et al. Clinical effectiveness and cost-effectiveness of endobronchial and endoscopic ultrasound relative to surgical staging in potentially resectable lung cancer: Results from de ASTER randomized controlled trial. Health Technol Assess 2012;16:1-75. 